\title{
Life First: The Strategy for The Chinese Police Under Normalization Stage of Prevention and Control of COVID-19
}

\author{
Cai Mengsheng ${ }^{1, a}$, Yan Zhenliang, ${ }^{2,}$ \\ ${ }^{1}$ Jiangsu Police Institute, Nanjing, Jiangsu, China \\ 2 Jiangsu Police Institute, Nanjing, Jiangsu, China \\ a 694667707@qq.com \\ b*Corresponding author.Email:250075937@qq.com
}

\begin{abstract}
In order to better respond to the challenge of regular COVID-19 viruses' prevention and control, Chinese police always put people's interests first, putting people's lives first. Under the unified deployment of the Joint prevention and control mechanism of The State Council, the police implemented the decision and deployment of the central government through a series of measures, adhered to and developed the "Fengqiao experience" in the new era, did a good job in the prevention and control work of foreign imports, and paid close attention to the prevention and control work of the police themselves. Chinese police have made sure that all the requirements for epidemic prevention and control have been carried out to the letter. Effectively contain the spread of the epidemic, safeguard national political security and maintain overall social stability.
\end{abstract}

Keywords: Chinese police, Normalizing prevention and control, Life First

\section{INTRODUCTION}

Handling the epidemic has a direct bearing on people's lives, health and safety. COVID-19 is a major public health concern in domestic and at abroad, and is still a global pandemic. According to official WHO statistics, as of 13 August 2021, there have been 205,338,159 confirmed cases of COVID-19 worldwide, including 4,333,094 deaths ${ }^{[1]}$. During the normal prevention and control normalization stage of COVID-19, China has effectively controlled the occurrence and spread of the epidemic by adopting the strategy of "preventing imported cases from abroad and preventing the rebound from domestic", effectively reducing the number of deaths and achieving rapid social and economic recovery. These measures have been highly recognized by the public, and the positive trend of the epidemic has been consolidated ${ }^{[2]}$. Studying the advanced experience of The Chinese police is of great significance for other countries in the world to better prevent and control the epidemic ${ }^{[3]}$. On the basis of introducing the working mechanism of epidemic prevention and control in China, this study comprehensively presents the advanced practices of
Chinese police and puts forward countermeasures and suggestions.

\section{THE OPERATIONAL MECHANISM OF THE CHINESE POLICE FOR EPIDEMIC PREVENTION AND CONTROL}

In order to better respond to the epidemic, the Ministry of Public Security has actively responded to the unified arrangements of The State Council and established a top-down, efficient, precise and orderly epidemic prevention and control mechanism.

At the national level, the Ministry of Public Security, as one of the members of the Joint prevention and control mechanism of The State Council ${ }^{[4]}$, immediately launched the Epidemic Prevention and Control Headquarters of the Ministry of Public Security upon receiving relevant instructions to study and deploy the police to prevent and control the epidemic and maintain security and stability. While carrying out normal police work and cracking down on crimes, local police actively cooperate with the Health Commission and other functional departments to do prevention and control work ${ }^{[5]}$. According to their respective duties, the police 
and auxiliary police have been working on the front line of epidemic prevention and control on a regular basis.

\section{PREVENTION AND CONTROL FRAMEWORK}

In the process of epidemic prevention and control, Chinese police always put people and life first ${ }^{[6]}$. According to the unified deployment of the Ministry of Public Security, Chinese Police have normalized their epidemic prevention and control work mainly in the following aspects.

1) Especially in epidemic prevention and control of the critical moment, the police at all levels effectively raise, political implementation, political sense, political understanding to the party and the people's highly responsible spirit, as the pinnacle of the current epidemic prevention and control work, strictly from solid fine pays special attention to the epidemic prevention and control and implement all the work and measures to maintain social stability.

2) The police at all levels should strengthen the collaboration with health, industry and information technology departments, constantly optimize the working mechanism, and cooperate with the work of source tracing and "epidemiological investigation"(EI, which is the core link of locating the source of infection and cutting the chain of epidemic transmission), so as to effectively support precision prevention and control. At the same time, the police at all levels severely cracked down on all kinds of illegal and criminal activities related to the epidemic in accordance with the law.

3) Always maintain a high level of political acumen and political discrimination, put to maintain political and security in the first place, resolutely resist will borrow coronavirus traceability to national attack smear of bad behavior, in accordance with law, investigate all kinds of harmful information on the net and manufacture of the illegal behavior of spreading rumours.

4) Police at all levels to further outbreak situation change on the likely impact of social stability, upholding and developing the new age, "Fengqiao experience" adhere to grasp catch a little earlier, under the leadership of the party committees and governments, to carry out the good apanage management responsibility and source control measures, actively involved that plague disputes help solve work, problem solving at the grassroots level, solve the maximum at the initial stage.

5) The police at all levels have further tightened the exit and entry policies, strictly examining and issuing exit and entry documents for citizens. We will further strengthen border control, tighten the grid management of border vehicles and social meetings, carry out intensive campaigns against crimes that interfere with border management, and crack down on illegal entry and exit activities such as smuggling.

\section{ACTUAL CASES OF CHINESE POLICE IN EPIDEMIC PREVENTION AND CONTROL}

\subsection{Carry out epidemiological investigation and transfer work}

Since the outbreak of the epidemic at Nanjing Lukou Airport, According to the deployment of the Municipal Joint Prevention and Control work Headquarters, Nanjing Public Security Bureau, together with other health departments, has set up a " Epidemiological Investigation and Operation Center"[7] .Tracing the specific time track of positive patients, identifying suspected contacts and secondary contacts, providing data support for precise prevention and control.

1) Pooling resources. The" Epidemiological Investigation and Operation Center" gathers 50 health experts and 80 public security police in a group of five to six, who are responsible for the division of labor and bound to fight. The centre takes the lead to take charge of the source of the trip and telephone return visit, and the front three-person team conducts field investigation and meets and checks, which breaks the original three-level instruction transmission and feedback mode of city, district and community, and achieves "point-to-point interaction and integrated response".

2) Make all-out efforts to encircle and intercept. In view of the high veracity and rapid spread of the Delta virus, the center expanded the encircle as much as possible, and followed the strategy of "encircle and intercept" to ensure that the epidemic prevention work ran ahead of the spread of the virus.

3) Quick and accurate verification. Center relying on the "big data + grid + iron soles" mechanism, with the fastest speed development cases of catenary, contact personnel screening out, according to "finding, landing, disposing" principle, reduce the links, compression process, directly notify the front 3 team, quickly landing to see people, implement the disposal measures. In terms of health code management, the center takes various ways to verify the real travel information.

\subsection{Investigate and handle illegal and criminal activities according to law}

In the process of law enforcement, Nanjing Police insisted on the purpose of ensuring epidemic prevention order. On the one hand, they resolutely investigated and dealt with cases of obvious subjective malice, serious damage or disturbance to the normal epidemic prevention order, and organized or assisted others to 
evade inspection at inspection sites. On the other hand, if the public does not understand the epidemic prevention and control policy, does not implement the relevant regulations, the harm is relatively light, and can promptly recognize the mistake after criticism and education, the punishment will be lighter, mitigated or not punished ${ }^{[8]}$.

\section{THE WAY FOR POLICE TO WIN THE BATTLE OF EPIDEMIC PREVENTION AND CONTROL ON NORMALIZATION STAGE}

1) The political nature of Chinese police. Speaking politics is a fine tradition of our Party, and paying attention to political construction is our Party's consistent and highly conscious [9]. Without this high level of consciousness, the soul of the police force is lost, the development direction is lost, and the original mission is lost. In each critical stage of epidemic prevention and control, the Chinese police have been able to put people first, always adhere to life first, and the fundamental factor is not political.

2) The public nature of Chinese police. In China, the full name of the police is the People's police ${ }^{[10]}$, and the public security refers to the people's police in a broad sense. The most important reason why the prevention and control of the epidemic on normalization stage has achieved a major victory in a short period of time is that the people are very popular.

3) The rule of law of Chinese police. In the process of epidemic prevention and control, all kinds of illegal and criminal activities related to the epidemic have not stopped. Interpol has issued early warnings to the public on risks such as counterfeit medical supplies and medicines, network security and telecom fraud [11]. Chinese police enforce the "Fengqiao Experience" will be implemented in daily police work, and the uninformed or minor illegal acts will be given lighter, mitigated or not punished, so as to establish the authority of the rule of law and guide the public to consciously abide by the law.

4) Discipline of Chinese police. Many police have been unable to go home for days, wearing airtight protective clothing in temperatures of over 30 degrees, working for more than 10 hours in a row, and walking more than 20 kilometers a day for community screening ${ }^{[12]}$, so as to ensure the prevention and control of the epidemic with "iron feet"(it's means, the police went from one house to another on their feet). Without iron discipline, it is difficult to organize a team with full combat effectiveness to carry out epidemic prevention and control work.

\section{CONCLUSION}

As the impact of the mutant strains of COVID-19, represented by Delta and Ramda, the prevention and control of the epidemic is a complex and systematic project, which requires the efforts of the whole society. Chinese police always put people and life first. This study is based on existing practices, but with the development of epidemic prevention and control, it is necessary to strengthen research on community emergency management, police handling of emergencies, big data information investigation, material support and lending, etc. In the future, there may be a more complicated and difficult situation in the prevention and control of COVID-19, but The Chinese police will continue to face the difficulties head on and take concrete actions to protect people's lives and safety.

\section{FOUNDATION PROJECT}

This research was supported by the "Qinglan Project" for Jiangsu Province. A Part of the Social Science Foundation of Jiangsu Province (20SHB001), Community emergency management and police practice under public health emergencies (ZK2030), the Soft Science Project of Ministry of Public Security (2020LLYJJSST058), and the Philosophy and Social Science Research of Jiangsu Police Institute ( 2020SJYS06 ).

\section{REFERENCES}

[1]WHO.(2021)WHO Coronavirus (COVID-19) Dashboard Overview Data Table. https://www.who.int/emergencies/diseases/novel-c oronavirus-2019.

[2]Liang W.N. et al. Experience and thinking in the normalization stage of COVID-19 prevention and control in China (2021)Chinese Medical Journal, 10:695-699.

[3]Zhang Q.L. Role of public security organs in prevention and control of public health emergencies and countermeasures (2021)Journal of Beijing Police College, 3:21-26.

[4]The NHC and other relevant departments have made joint efforts to combat the novel coronavirus outbreak. Chinese government network. 2020-01-22.

[5]Wang W. Research on the prevention and control of major outbreaks by public security (2020)Journal of Fujian police college, 3:12-20.

[6]The rule of law journal .(2021)All-out efforts will be made to prevent and control the epidemic and safeguard social stability. 
https://baijiahao.baidu.com/s?id=17076506614119 $46844 \& w f r=$ spider $\&$ for $=$ pc.

[7]Nanjing Public Security Bureau. (2021)Nanjing public security "flow adjustable operations centre" power epidemic prevention and control accurately. http://gaj.nanjing.gov.cn/jwdt/202108/t20210803_3 091330.html.

[8]Nanjing Public Security Bureau. (2021)The police reported six kind of rumour, breach of prevention and control of typical case. http://gaj.nanjing.gov.cn/aqff/202108/t20210806_3 096020.html.

[9]Zhou C.M., Li Y.X.. A Multi-dimensional analysis of $\mathrm{Xi}$ Jinping's Police Thought in the New Era (2021)Journal of Sichuan Police College, 8: 1-9.
[10] 《People's Police Law of the People's Republic of China》, 2012.

[11]International Criminal Police Organization. Criminals don't take breaks. (2021)Even as everything around us is being put on hold, they are looking for new ways to generate profits. https://www.interpol.int/How-we-work/COVID-19 /COVID-19-Stay-Safe.

[12]Jiangsu Police. (2021)Is war "epidemic" imprinting, is most beautiful stamp. https://mp.weixin.qq.com/s/48VZCKoDDQyZOhC PLxRk0g. 